\title{
Modelling the Digital Supply Chain enablers using TISM and MICMAC approach
}

DOI : 10.36909/jer.ICIPPSD.15537

\author{
Vimal Kumar Dixit*, Rakesh Kumar Malviya, Shrikant Pandey
}

Department of mechanical engineering, Shri Vaishnav Vidyapeeth Vishwavidyalaya, Indore *Email: vimaldixit06@gmail.com; Corresponding Author.

\begin{abstract}
The purpose of this article is to select digital supply chain enablers (DSCEs) to find its contextual relationship for successful digital supply chain (DSC) implementation. Total interpretative structural modelling (TISM) is used to develop the relationship among selected DSCEs. The findings of TISM are worked for the Matriced Impacts Croises Multiplication Appliqueeaun Classement (MICMAC) approach to identify the driving and dependence power of DSCEs. This paper identified 10 DSCEs and developed an integrated model using TISM and the FMICMAC approach. The model is used to recognize and organize the important enablers and show the direct and indirect relationship and effects of each enabler on the DSC implementation.
\end{abstract}

Key words: digital supply chain; digital supply chain enablers; total interpretive structural modelling; MICMAC.

\section{INTRODUCTION}

Digital technologies almost changed the system the people will connect and intermingle around them. New scientific innovations and tools shift the manner how companies' use and share information (Mentzer et al., 2001). Digital Supply Chain (DSC) is a novel for organizations concern with new digitized analytical approach for effective supply chain (SC). DSC is the process of managing the SC using adoption of innovative technologies (Buyukozkan \& Goçer, 2018). Digital adaptation is the main component to compete in today's commercial ecosphere because of rapid pace of innovations. There were several benefits of using DSC for manufacturing organizations, however the DSC implementation is not an easy task because it involves many risks, high capital investment and changes involved. However, DSC has some enablers which enhances the probability of its implementation. Some of the enablers identified within the literature are real-time analysis of the company, better overall SC decisions. Thus, it 
is important to establish the interrelationship between DSC enablers. Analysis of the enablers increases the probability of DSC implementation and enablers interrelationship can provide significant evidence to management. This study investigates the enablers to DSC based on present literature survey and belief of selected experts. DSC implementation is generally supported by these enablers. Total Interpretive structural modelling (TISM) is an important method for finding relations between identified parameters. TISM is an advanced version of ISM which involves qualitative modeling technique (Sushil, 2012; Dubey et al., 2017; Jena et al., 2016). In present work, DSCEs have been analyzed using the TISM and Matriced Impacts Croises Multiplication Appliqueeaun Classement (MICMAC) method, that provides mutual relationship of different DSCEs, their driving and dependence power.

This paper contains four sections. Section one presents introduction of this work; Section two contains the literature of DSC and identification of various DSCEs; Section three presents the TISM method and its steps for modelling DSCEs and then brief description of MICMAC analysis and categorizing the DSCEs into different clusters. Section four presents the conclusions of this research.

\section{LITERATURE REVIEW}

Radanliev et al., (2019) studies the planning principles for emerging perception within the procedure of mixing small and medium scale industries digital supply chains within the Industrial Internet of Things. Digital adaptation needs to understand consumers wants and demands throughout their life. DSC is related to manage supply chain processes with the help of wide variety of innovative technologies (Büyüközkan and Göçer, 2018). Penthin and Dillman, 2015 finds that regarding three fourth of the people across the globe can now have internet facility while 50 per cent amongst these people are using social media. additionally, almost every internet user using online shopping. This high use of digital platform has changed consumers purchasing actions. Everyone can buy online from abroad also due to which volatility in demand have increased. Use of new digital tools can be useful for minimizing some competitions (Farahani et al., 2015). To deal with competition challenges, industries from different areas or streams are fusing investment to digitize its SC. Mueller et al. (2018) finds that almost three-fourth of production companies are effectively increasing their level of digitization by 2020. Digitalization of SC have high probability to have customer satisfaction, increased visualization, healthier association within SC (Pradabwong et al., 2017). Various industries around the globe have tried adopting DSC but only a few are satisfied with their approach (Dougados and Felgendreher, 2016). A modern estimation framework with the application of ERP is prepared, which makes continuously analysis of 
sellers at each delivery (Tekez et. al.,2019). The number of companies failed to require business gain of digitization because of the lack of research in the area and absence of supporting DSCEs (Agrawal et al. 2019). Some of the enablers obtained through extensive literature review are given in table 1.

Table 1. DSCEs

\begin{tabular}{ll} 
DSC Name of DSCEs & \multicolumn{1}{l}{ Description } \\
Es &
\end{tabular}

E2 Better overall SCM The decision regarding overall decisions

E3 Increased flexibility

$\mathrm{SCM}$ increasing company's image.

Flexibility is an important differentiator in the current marketplace. The need to incorporate flexibility to react to changing customer demand.

E4 Lower inventory and The Cost reduction in inventory warehousing cost

management is significant in a
market that is continuously
attracting more competition. As
competition grows, logistics
businesses must take a couple of
simple steps to level back
inventory costs to remain within
the competition.
Digital concepts such as

E5 Lower supply chain Digital concepts such as
risk analytics, unmanned aerial vehicles, and fewer distribution facilities reduce total supply chain risks. SC risk develops from different areas, as natural calamities, during war or terrorism, supplier economic failure etc.

E6 More efficient supply An efficient SC minimizes chain

E7 Higher product and Products and Services which service quality costs, reduces time, and maximum resource utilization.

fulfills customers need and wants results in customer
Authors

Penthin \& Dillman (2015), Hines, (2004)

Schmidt et al, (2015), Cecere, 2016

$\mathrm{Xu}, \quad$ (2014), Sharma et.al., (2014), Cecere, (2016)

Schmidt et al, (2015), Hanifan et al, (2014), Cecere,2016, Agrawal \& Narain, (2018)

Rakowski, (2015), Cecere, (2016), Agrawal \& Narain, (2018)

Hanifan et al, (2014), Cecere,(2016), Raj \& Sharma (2014)

Raj \& Sharma (2014), Schmidt et al, (2015), Rakowski, (2016), 
satisfaction. Quality is the fits for purpose or use and fulfill Cecere,(2016) customers' expectations. Product quality designates a product's capability to meet customers' standards. It creates faith with your customers which reduces customer complaints and bad feedback.

E8 Robust inbound Reliable and robust supply supply chain chains influence the cost and reduce the risk of not obtaining

Rakowski, Cecere, (2016) (2016), a supply. Reliable chains have fewer chances of disruption, whereas robust chains still perform very well in the case of disrupted supply channels.

E9 Lower transport and The real-time information on the Schmidt et al, (2015) logistics use of resources in the administration cost warehouse, Lower transport Dougados, \& and logistics administration cost due to optimized operations like design of optimal picking routes and machine programming.

E10 Lower supply chain If the company has more than complexity one supply chains, then it can Raj \& Sharma (2014), reduce supply chain complexity. Analysis of those into their natural segments, they become more easily understood and managed. $\&$ 


\begin{tabular}{|c|c|c|c|c|c|c|c|c|c|c|}
\hline $\mathbf{j}$ & \multirow{2}{*}{ E1 } & \multirow{2}{*}{ E2 } & E3 & E4 & E5 & E6 & E7 & E8 & E9 & E10 \\
\cline { 1 - 9 } E1 & 1 & $\mathrm{X}$ & $\mathrm{V}$ & $\mathrm{V}$ & $\mathrm{V}$ & $\mathrm{V}$ & $\mathrm{V}$ & $\mathrm{V}$ & $\mathrm{V}$ & $\mathrm{V}$ \\
\hline E2 & & 1 & $\mathrm{X}$ & $\mathrm{V}$ & $\mathrm{V}$ & $\mathrm{V}$ & $\mathrm{V}$ & $\mathrm{V}$ & $\mathrm{V}$ & $\mathrm{V}$ \\
\hline E3 & & & 1 & $\mathrm{~V}$ & $\mathrm{~V}$ & $\mathrm{~V}$ & $\mathrm{~V}$ & $\mathrm{~V}$ & $\mathrm{O}$ & $\mathrm{V}$ \\
\hline E4 & & & & 1 & $\mathrm{X}$ & $\mathrm{A}$ & $\mathrm{O}$ & $\mathrm{O}$ & $\mathrm{O}$ & $\mathrm{O}$ \\
\hline E5 & & & & & 1 & $\mathrm{X}$ & $\mathrm{A}$ & $\mathrm{A}$ & $\mathrm{O}$ & $\mathrm{A}$ \\
\hline E6 & & & & & & 1 & $\mathrm{~V}$ & $\mathrm{~A}$ & $\mathrm{~V}$ & $\mathrm{~V}$ \\
\hline E7 & & & & & & & 1 & $\mathrm{~A}$ & $\mathrm{O}$ & $\mathrm{A}$ \\
\hline E8 & & & & & & & & 1 & $\mathrm{~V}$ & $\mathrm{~V}$ \\
\hline E9 & & & & & & & & & 1 & $\mathrm{~A}$ \\
\hline E10 & & & & & & & & & & 1 \\
\hline
\end{tabular}

Step IV: The SSIM has been converted into a binary matrix, called the initial reachability matrix, by substituting $\mathrm{V}, \mathrm{A}, \mathrm{X}$ and $\mathrm{O}$ by 1 and 0 , as per the given case taken from the referred article.

Step V: The initial reachability matrix is checked for transitivity according to rule, if "a relates to b" and "b relates to c" these imply "a necessarily relates to c." Accordingly, the final reachability matrix with transitive links is prepared (table 3 ).

Table 3 Final Reachability matrix

\begin{tabular}{|c|c|c|c|c|c|c|c|c|c|c|}
\hline $\begin{array}{l}\mathbf{J} \\
\mathbf{I}\end{array}$ & E1 & E2 & E3 & $\mathrm{E} 4$ & E5 & E6 & E7 & E8 & E9 & E10 \\
\hline E1 & 1 & 1 & 1 & 1 & 1 & 1 & 1 & 1 & 1 & 1 \\
\hline E2 & 1 & 1 & 1 & 1 & 1 & 1 & 1 & 1 & 1 & 1 \\
\hline E3 & $1 *$ & 1 & 1 & 1 & 1 & 1 & 1 & 1 & $1 *$ & 1 \\
\hline E4 & 0 & 0 & 0 & 1 & 1 & $1 *$ & 0 & 0 & 0 & 0 \\
\hline E5 & 0 & 0 & 0 & 1 & 1 & 1 & $1^{*}$ & 0 & $1 *$ & $1 *$ \\
\hline E6 & 0 & 0 & 0 & 1 & 1 & 1 & 1 & 0 & 1 & 1 \\
\hline E7 & 0 & 0 & 0 & 0 & 1 & $1 *$ & 1 & 0 & 0 & 0 \\
\hline E8 & 0 & 0 & 0 & $1 *$ & 1 & 1 & 1 & 1 & 1 & 1 \\
\hline E9 & 0 & 0 & 0 & 0 & 0 & 0 & 0 & 0 & 1 & 0 \\
\hline E10 & 0 & 0 & 0 & 0 & 1 & $1 *$ & 1 & 0 & 1 & 1 \\
\hline
\end{tabular}

Step VI: Level partition of the DSCEs is done by finding the reachability and antecedent set for each DSCEs. The common element of these sets is identified and for whom the reachability and the intersection sets are same were assigned a level (table 4).

Table 4 Level partition of DSCEs

\begin{tabular}{|c|c|c|c|c|}
\hline Enablers & Reachability set & Antecedent set & Intersection set & Level \\
\hline 1 & $1,2,3,4,5,6,7,8,9,10$ & $1,2,3$ & $1,2,3$ & IV \\
\hline 2 & $1,2,3,4,5,6,7,8,9,10$ & $1,2,3$ & $1,2,3$ & IV \\
\hline 3 & $1,2,3,4,5,6,7,8,9,10$ & $1,2,3$ & $1,2,3$ & IV \\
\hline 4 & $4,5,6$ & $1,2,3,4,5,6,8$ & $4,5,6$ & I \\
\hline 5 & $4,5,6,7,9,10$ & $1,2,3,4,5,6,7,8,10$, & $4,5,6,7,10$ & II \\
\hline 6 & $4,5,6,7,9,10$ & $1,2,3,5,4,6,7,8,10$, & $4,5,6,7,10$ & II \\
\hline \multicolumn{4}{|c}{5}
\end{tabular}




\begin{tabular}{|c|c|c|c|c|}
\hline 7 & $5,6,7$ & $1,2,3,5,6,7,8,10$, & $5,6,7$ & I \\
\hline 8 & $4,5,6,7,8,9,10$ & $1,2,3,8$ & 8 & III \\
\hline 9 & 9 & $1,2,3,5,6,8,9,10$ & 9 & I \\
\hline 10 & $5,6,7,9,10$ & $1,2,3,5,6,8,10$ & 5,6 & II \\
\hline
\end{tabular}

Step VII: TISM model development

Using Table 4, the TISM model is developed (Figure 1).

\section{Steps of MICMAC analysis}

The MICMAC method has two steps: first, a MICMAC graph is prepared using the driving and dependence power of DSCEs and based on it a MICMAC rank is obtained. The driving and dependence power of DSCEs is obtained by adding corresponding elements of row and corresponding elements column to obtain the final matrix.

The MICMAC graph is developed by locating the DSCEs on a graph using its driving and dependence power and classifying the graph into four categories namely autonomous variables, dependent variables, linkage variables and independent variables. The MICMAC graph is presented in Figure 2.

The analysis of MICMAC graph is as follows:

\section{Autonomous DSCEs}

Autonomous DSCEs are weak drivers and weak dependent. They do not influence the system. The MICMAC graph indicates that there is no autonomous enabler in the process of DSC implementation.

\section{Dependent DSCEs}

The dependent DSCEs have strong dependence but are weak drivers. Lower inventory and warehousing cost (DSCE4), higher product and service quality (DSCE7), Lower transport and logistics administration cost (DSCE9), and lower supply chain complexity (DSCE10) fall in this group. This shows that availability enablers minimise the effect of these DSCEs in DSC management.

\section{Linkages DSCEs:}

Linkage DSCEs have high driving power and high dependence. There are two DSCEs Lower supply chain risk (DSCE5) and more efficient supply chain (DSCE6) in this group. Any change occurring to these DSCEs will influence other enablers.

\section{Driving or Independent DSCEs:}


Driving or Independent DSCEs have high driving power and low dependence. Real-time analysis of the company (DSCE1), Better overall SCM decisions (DSCE2), Increased SCM flexibility (DSCE3), and Robust inbound supply chain (DSCE8) falls in this category. Thus, top management need to deal with these DSCEs more carefully, as these are the basis of handling all other DSCEs too

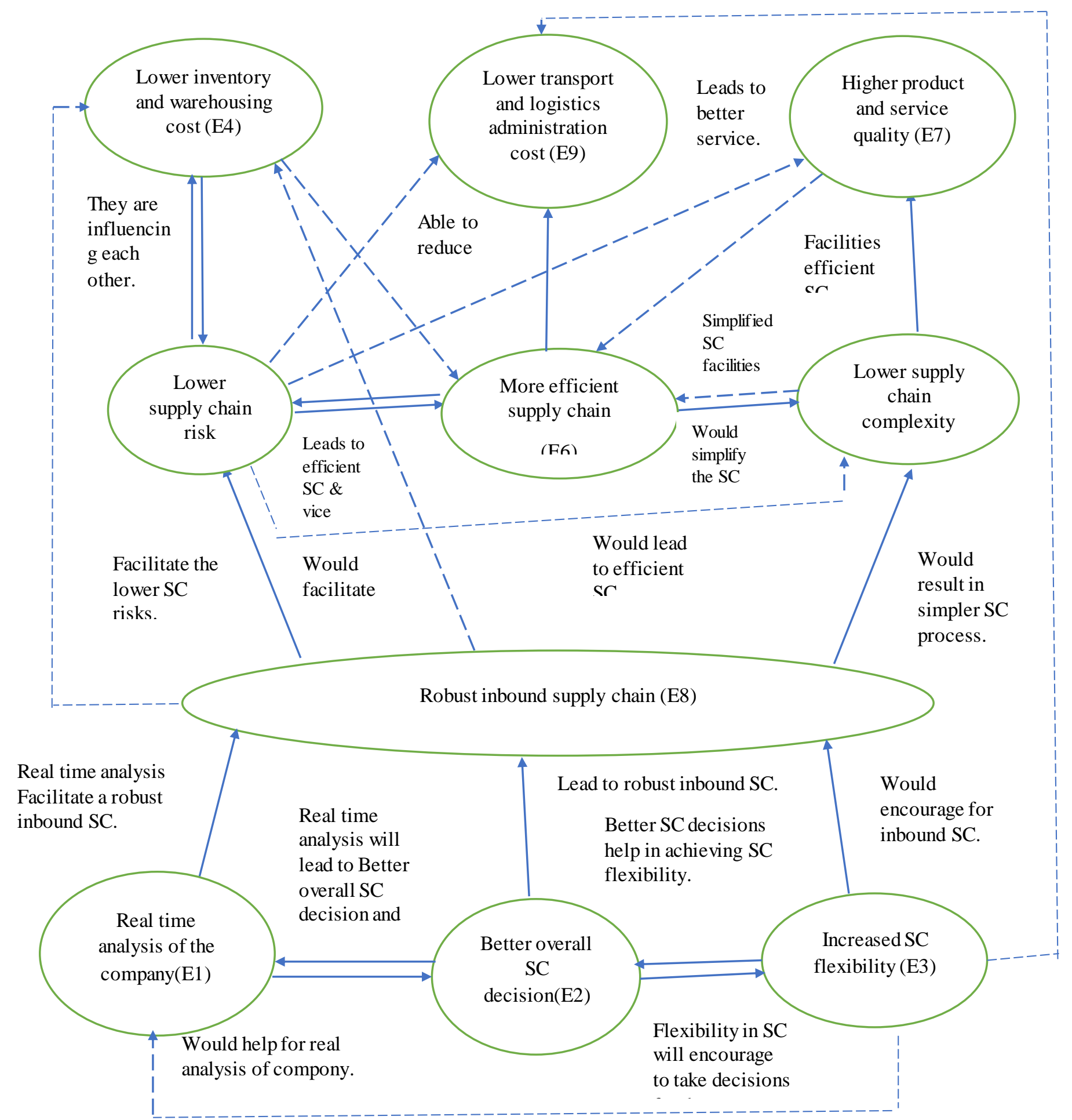

Figure 1 TISM model with significant transitive links 


\section{Direct link}

Transitive link

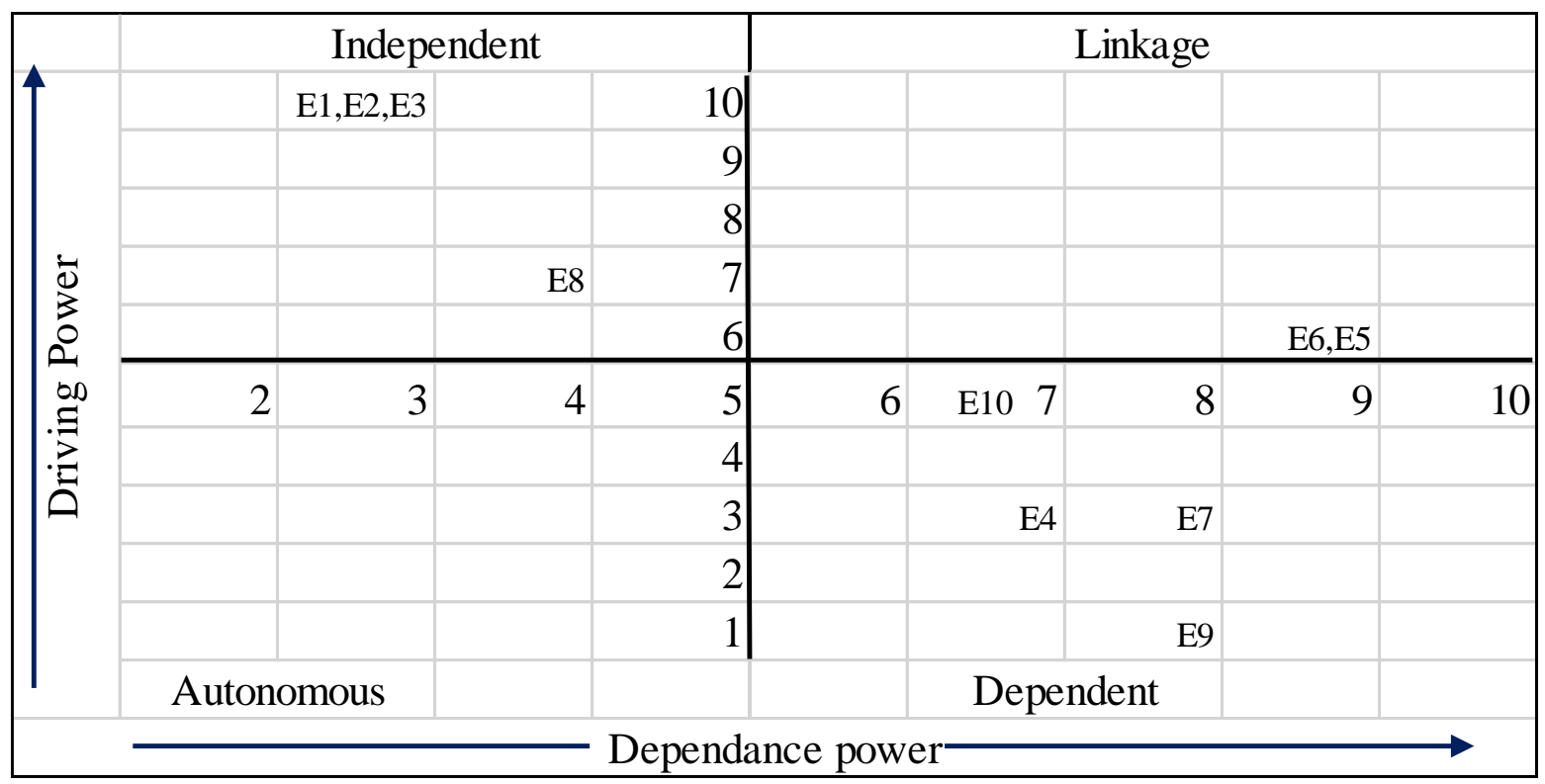

Figure 2 The MICMAC graph

\section{CONCLUSION}

The DSCEs are dependent on each other and have connections among them. It becomes more important to identify the relationship of DSCEs with each other. An integrated model of TISM and the MICMAC is developed that can be helpful for SC managers to use this model effectively. This may be helpful to find and categorize the essential DSCEs for their industrial benefits. The academician may use this model to effectively analyse the interdependencies of these identified DSCEs for successful DSC implementation.

\section{REFERENCES}

Agrawal, P., \& Narain, R. (2018, December). Digital supply chain management: An Overview. In IOP Conference Series: Materials Science and Engineering (Vol. 455, No. 1, p. 012074). IOP Publishing.

Agrawal, P., Narain, R., \& Ullah, I. (2019). Analysis of barriers in implementation of digital transformation of supply chain using interpretive structural modelling approach. Journal of Modelling in Management. 
Baker, G., Lomax, S., Braidford, P., Allinson, G., \& Houston, M. (2015). Digital capabilities in SMEs: Evidence review and re-survey of 2014 small business survey respondents. BIS Research Paper, 247.

Ben-Daya, M., Hassini, E., \& Bahroun, Z. (2017). Internet of things and supply chain management: a literature review. International Journal of Production Research, 1-24. doi:http://dx. doi.org/10.1080/00207543.2017.1402140.

Berman, S. J. (2012). Digital transformation: opportunities to create new business models. Strategy \& Leadership, 40(2), 16-24.

Brewster, C., Roussaki, I., Kalatzis, N., Doolin, K., \& Ellis, K. (2017). IoT in agriculture: Designing a Europe-wide large-scale pilot. IEEE communications magazine, 55(9), 2633.

Büyüközkan, G., \& Göçer, F. (2017). An extension of MOORA approach for group decision making based on interval valued intuitionistic fuzzy numbers in digital supply chain. In 2017 Joint 17th World Congress of International Fuzzy Systems Association and 9th International Conference on Soft Computing and Intelligent Systems (IFSA-SCIS) (pp. 16). IEEE.

Büyüközkan, G., \& Göçer, F. (2018). Digital supply chain: literature review and a proposed framework for future research. Computers in Industry, 97, 157-177.

Cecere, L. (2016). Embracing the digital supply chain. Supply Chain Shaman.

Cui, L., Gao, M., Dai, J., \& Mou, J. (2020). Improving supply chain collaboration through operational excellence approaches: an IoT perspective. Industrial Management \& Data Systems.

De Sousa, T. B., Melo, I. C., de Oliveira, P. H., Lourenço, C. M., Guerrini, F. M., \& Esposto, K. F. (2020). Balanced scorecard for evaluating the performance of supply chains: A bibliometric study. Journal of Engineering Research, 8(1).

Dougados, M.; Felgendreher, B. (2016): Digitale Transformation der Supply Chain - Stand heute und in 5 Jahren, http://mktforms.gtnexus.com/rs/979-MCL-531/images/GTNexusDigitale-Transformation-der-Supply-Chain\%E2\%80\%93Stand-heute-und-in-5Jahren.pdf, abgerufen am 28.10.2018. 
Dubey, R., Gunasekaran, A., Papadopoulos, T., Childe, S. J., Shibin, K. T., \& Wamba, S. F. (2017). Sustainable supply chain management: framework and further research directions. Journal of cleaner production, 142, 1119-1130.

Farahani P, Meier C, Wilke J (2015) A vision on a digital supply chain management. 360 Bus

Felgendreher, S., \& Lehmann, P. (2016). Public choice and urban water tariffs-Analytical framework and evidence from Peru. The Journal of Environment \& Development, 25(1), 73-99.

Gunasekaran, A., Papadopoulos, T., Dubey, R., Wamba, S. F., Childe, S. J., Hazen, B., \& Akter, S. (2017). Big data and predictive analytics for supply chain and organizational performance. Journal of Business Research, 70, 308-317.

Haddud, A., DeSouza, A., Khare, A., \& Lee, H. (2017). Examining potential benefits and challenges associated with the Internet of Things integration in supply chains. Journal of Manufacturing Technology Management, 28(8), 1055-1085.

Hanifan, G., Sharma, A., \& Newberry, C. (2014). The Digital Supply Network. A New Paradigm for Supply Chain Management, Accenture Strategy.

Hines, T. (2004). Supply chain strategies: Customer driven and customer focused. Routledge.

Jena, J., Fulzele, V., Gupta, R., Sherwani, F., Shankar, R., \& Sidharth, S. (2016). A TISM modeling of critical success factors of smartphone manufacturing ecosystem in India. Journal of Advances in Management Research.

Kumar, S., Gorane, S., \& Kant, R. (2015). Modelling the supplier selection process enablers using ISM and fuzzy MICMAC approach. Journal of Business \& Industrial Marketing.

Malviya, R. K., \& Kant, R. (2017). Modeling the enablers of green supply chain management. Benchmarking: An International Journal.

Manjunatheshwara, K. J., \& Vinodh, S. (2018). Application of TISM and MICMAC for analysis of influential factors of sustainable development of tablet devices: a case study. International Journal of Sustainable Engineering, 11(5), 353-364.

Mentzer, J. T., DeWitt, W., Keebler, J. S., Min, S., Nix, N. W., Smith, C. D., \& Zacharia, Z. G. (2001). Defining supply chain management. Journal of Business logistics, 22(2), 1 25 . 
Nasrollahi, M., Razmi, J., \& Ghodsi, R. (2019). A combined fuzzy PCA approach for location optimization and capacity planning in Glycyrrhizae green supply network design. Journal of Engineering Research, 7(4).

Penthin, S., \& Dillman, R. (2015). Digital SCM. www. bearingpoint. Com.

Pradabwong, J., Braziotis, C., Tannock, J. D., \& Pawar, K. S. (2017). Business process management and supply chain collaboration: effects on performance and competitiveness. Supply Chain Management: An International Journal.

Raab, M. \& Griffin-Cryan, B. (2011), Digital Transformation of Supply Chains: Creating Value - When Digital Meets Physical, Capgemini Consulting.

Radanliev, P., De Roure, D. C., Nurse, J. R., Montalvo, R. M., \& Burnap, P. (2019). The Industrial Internet-of-Things in the Industry 4.0 supply chains of small and medium sized enterprises. University of Oxford, 10.

Raj, A., Dwivedi, G., Sharma, A., de Sousa Jabbour, A. B. L., \& Rajak, S. (2020). Barriers to the adoption of industry 4.0 technologies in the manufacturing sector: An inter-country comparative perspective. International Journal of Production Economics, 224, 107546.

Rajesh, R. (2017). Technological capabilities and supply chain resilience of firms: A relational analysis using Total Interpretive Structural Modeling (TISM). Technological Forecasting and Social Change, 118, 161-169.

Rakowski, E. (2015). Tech trends 2016. Part II: The supply chain goes digital. Procurement Leaders.

Simchi-Levi, D., Schmidt, W., Wei, Y., Zhang, P. Y., Combs, K., Ge, Y., \& Zhang, D. (2015). Identifying risks and mitigating disruptions in the automotive supply chain. Interfaces, 45(5), 375-390.

Song, D. P., Dong, J. X., \& Xu, J. (2014). Integrated inventory management and supplier base reduction in a supply chain with multiple uncertainties. European Journal of Operational Research, 232(3), 522-536

Sushil (2012). Interpreting the Interpretive Structural Model. Global Journal of Flexible Systems Management, 13(2), 87-106.Transform J (13).

Tekez, E. K., Kar, F., \& Toklu, M. C. (2019). A new model for continuous evaluation of suppliers with real execution data. Journal of Engineering Research, 7(2). 
Journal of Engg. Research, ICIPPSD Special Issue 